\title{
Effect of chlorpyrifos on survival, growth and reproductive performance of Eudrilus eugeniae (Kinberg)
}

\author{
S. S. Hundal ${ }^{*}$, R. Kaur ${ }^{1}$ and Avneet Kaur ${ }^{1}$ \\ Department of Zoology, College of Basic Sciences \& Humanities, Punjab Agricultural University, Ludhiana, INDIA \\ *Corresponding author. E-mail: sshundal@pau.edu
}

Received: December 15, 2015; Revised received: June 05, 2016; Accepted: August 21, 2016

\begin{abstract}
The present laboratory study was conducted to determine the effect of chlorpyrifos on growth and reproduction of the earthworm Eudrilus eugeniae. Chlorpyrifos was mixed with soil substrate at four different dose formulations i.e. D1 $(2.5 \mathrm{ml} / 1000 \mathrm{ml}) ; \mathrm{D} 2(5.0 \mathrm{ml} / 1000 \mathrm{ml}) ; \mathrm{D} 3(7.5 \mathrm{ml} / 1000 \mathrm{ml}) ; \mathrm{D} 4(10.0 \mathrm{ml} / 1000 \mathrm{ml})$. Soil substrate without chlorpyrifos served as control. Growth and survival rates were determined till four weeks and effects on reproduction are assessed after eight weeks of exposure. A non significant decrease $(p>0.05)$ was observed in body weight of earthworms which was recorded on day 1,2, 3, 7, 10 and 14. A dose dependent effect on cocoon production and survivability of hatchlings was observed in all treated groups. The effect of chlorpyrifos on life cycle of earthworm was more in dose D3 (54.25 days) when compared to control ( 28.75 days) while no worm survived in D4 dose. The present study revealed that chlorpyrifos at high dose levels $(7.5 \mathrm{ml} / 1000 \mathrm{ml}$ and $10.0 \mathrm{ml} / 1000 \mathrm{ml})$ affect the reproduction and growth of earthworms, primary bioindicators of soil fauna, whereas the base dose $(5.0 \mathrm{ml} / 1000 \mathrm{ml}) \mathrm{may}$ be considered as safe for soil applications.
\end{abstract}

Keywords: Chlorpyrifos, Eudrilus eugeniae, Growth, Reproduction

\section{INTRODUCTION}

With increasing demand for food and fiber, agriculture has to depend on the use of pesticides and fertilizers for high yields which leads to environmental contamination varieties. The use of pesticides has increased with the increasing awareness of their utility in agriculture, animal husbandry, and post harvest technology and in public health worldwide (Muthuviveganandavel et al., 2008). Chlorpyrifos is a broad spectrum organophosphate insecticide effective against a large number of agricultural and household pests. In India, it is widely recommended for seed treatment against white grub and termites and persists in the soil for 3-4 months (Kurawar, 2010). The wide spread use of pesticide protect the floral diversity against the particular pest but also affect the non target fauna (Muir et al., 2004). Earthworms are common soil organisms in most environments and play an important role in improving structure and fertility of soil ecosystems (Georgescu and Werber, 2007; Bartllet et al., 2010) by modifying soil organic matter both chemically and physically, facilitating the formation and stabilization of soil aggregates and improving soil porosity. Earthworms have sensitive receptors on their body surfaces with which they sense chemicals in the soil (Haque and Ebing, 1983) and thus are good bioindicators of soil providing safety thresholds for insecticide applications (Suthar et al., 2008; Lourenco et al., 2011). Earthworms constitute about $60-80 \%$ of total soil biomass
(Ouellet et al., 2008; Jouquet et al., 2010) and when exposed to pesticides and heavy metals may experience physiological disturbances such as a reduction in biomass, population size and reproduction as well as lysosome deficiencies (Ricketts et al., 2004; Spurgeon et al., 2004). Eudrilus eugeniae (African night crawler) is used extensively for composting in tropics, especially in Africa and India. This species is more productive in terms of rates of growth than other species of earthworm. Changes in growth and reproductive parameters of earthworms exposed to agro-pesticide loaded soils seem to be useful indicators of soil pollution. The present study was carried out to determine the effect of chlorpyrifos on survival, growth and reproduction of Eudrilus eugeniae (Kinberg).

\section{MATERIALS AND METHODS}

Stock: E. eugeniae was cultured in cement concrete rings containing farmyard manure (FYM) substrate in the Department of Zoology, PAU, Ludhiana. The FYM was collected from the livestock farm, located at GADVASU, Ludhiana. Earthworms in pre-clitellar and clitellar phase of life cycle were used during the study.

Experimental dose and collection of soil sample: Considering the dose recommended by PAU as base $(5.0 \mathrm{ml} / 1000 \mathrm{ml})$ different doses viz D1 $(2.5 \mathrm{ml} / 1000 \mathrm{ml}), \quad \mathrm{D} 2 \quad(5.0 \mathrm{ml} / 1000 \mathrm{ml}), \quad \mathrm{D} 3$ $(7.5 \mathrm{ml} / 1000 \mathrm{ml})$ and $\mathrm{D} 4(10.0 / 1000 \mathrm{ml})$ were prepared in water to access the toxicity of chlorpyrifos on 
growth and reproduction. The soil sample collected from the experimental fields of PAU campus as control consisted of $80 \%$ soil and $20 \%$ farm yard manure and sterilized in an autoclave as per standard procedure.

Effect on growth and reproductive performance:

E. eugeniae were added to $500 \mathrm{mg}$ of soil mixed with different doses of chlorpyrifos described above in plastic trays to study the effect on growth and survival. To avoid moisture loss the plastic trays were covered with perforated plastic lids/moist cloth. The experiment was carried out for 14 days and worm's survival/ activity was evaluated on days 1, 2, 3, 7, 10 and 14. Reproductive performance of adult E. eugeniae was estimated by placing one pair of earthworm in plastic tray containing 250-300 gm of the soil substrate sample treated with chlorpyrifos. Rate of reproduction was assessed on the basis of the number of cocoons produced per adult worm at each dose treatment following the method of Sahu and Senapati (1988).

Statistical analysis: The experiments were replicated in triplicate and the data was statistically analyzed by Analysis of Variance (ANOVA) using computer software CPCS1.

\section{RESULTS}

Body weight of worms exposed to chlorpyrifos at different days is shown in Table 1. A non significant decrease $(p>0.05)$ in body weight was noted in control and treated groups. The effect of chlorpyrifos on cocoon production rate was dose dependent as indicated by the decrease in value (Table 2 ) in different doses: D1 (1.34 \pm 0.04$)$; D2 (1.5 \pm 0.08$)$; D3 (1.36 \pm 0.06$)$; D4 $(1.3 \pm 0)$. A similar trend was observed in hatchling production rate and hatchling per cocoon per week with the hatchlings emerging from cocoons in the fourth week in control (Table 3). The dozed substrates had hatchlings only in the $5^{\text {th }}$ week which is a delayed occurrence. Interestingly, no hatchlings were observed in the $7^{\text {th }}$ week in doses D2, D3 and D4, while low hatchability was observed in D1 and control. The values of percentage survivability of hatchlings are the strong pointers that this effect is dose dependent and not species specific (Table 4). Maximum survivability was observed in D1 dose when compared with control where as no worm survived in D4 dose. A significant increase $(\mathrm{p}<0.05)$ in the body weight was observed in $8^{\text {th }}$ week of experiment in control, D1and D3 dose where as in D2 maximum weight gain was observed during $6^{\text {th }}$ week of the experiment (Table 5). No worm survived in D4 beyond one week of exposure. Total time taken by $E$. eugeniae, from the emergence of hatchlings to reach adult stage with a fully developed clitellum was recorded to be $28.75 \pm 0.82 ; 43.25 \pm 0.82 ; 45.75 \pm 0.82 ; 54.25 \pm 0.82$ days in control, D1, D2 and D3 respectively. No worms survived in D4 dose application (Table 6).

\section{DISCUSSION}

As earthworms play an important role as engineers in many soils, they have become standard test organisms in ecotoxicology due to their easy handling and culturing. Reduction in body weight of worms indicates the physiological reaction of the organism to insecticide exposure and the changes in earthworm's body mass are thought to be of ecological relevance. It has been assumed by earlier workers that high losses in body mass may lead to negative effects on reproduction and survival (Capoweiz et al., 2005; Olvera-Velona et al., 2008) and is relevant in the observations recorded dur-

Table 1. Changes in body weight (g) of E. eugeniae in different doses of chlorpyrifos exposed on different days.

\begin{tabular}{ccccccc}
\hline \multirow{2}{*}{ Doses } & \multicolumn{7}{c}{ Days } \\
\cline { 2 - 7 } & $\mathbf{1}^{\text {st }}$ day & $\mathbf{2}^{\text {nd }}$ day & $\mathbf{3}^{\text {rd }}$ day & $\mathbf{7}^{\text {th }}$ day & $\mathbf{1 0}^{\text {th }}$ day & $\mathbf{1 4}^{\text {th }}$ day \\
\hline D1 & $0.45 \pm 0.01$ & $0.44 \pm 0.02$ & $0.42 \pm 0.02$ & $0.42 \pm 0.03^{*}$ & $0.40 \pm 0.03^{*}$ & $0.40 \pm 0.007^{*}$ \\
D2 & $0.44 \pm 0.04$ & $0.43 \pm 0.03$ & $0.39 \pm 0.03$ & $0.36 \pm 0.08^{*}$ & $0.33 \pm 0.08^{*}$ & $0.33 \pm 0.07^{*}$ \\
D3 & $0.37 \pm 0.02$ & $0.36 \pm 0.05$ & $0.37 \pm 0.02$ & $0.41 \pm 0.01^{*}$ & $0.44 \pm 0.005^{*}$ & $0.39 \pm 0.005^{*}$ \\
D4 & $0.42 \pm 0.02$ & $0.35 \pm 0.05$ & $0.34 \pm 0.05$ & $0.30 \pm 0.05^{*}$ & $0.34 \pm 0.05^{*}$ & $0.34 \pm 0.04^{*}$ \\
Control & $0.43 \pm 0.02$ & $0.42 \pm 0.03$ & $0.44 \pm 0.02$ & $0.33 \pm 0.04$ & $0.33 \pm 0.04$ & $0.32 \pm 0.01$ \\
\hline
\end{tabular}

D1, D2, D3 and D4 are the chlorpyrifos dose samples i.e. $2.5,5,7.5,10 \mathrm{ml} / 1000 \mathrm{ml}$; Values are Mean \pm S.E of four replicates; $*$ Values are significant at $5 \%$ level of significance

Table 2. Cocoon production rate (cocoon/worm/week) and total number of cocoons produced by E. eugeniae different doses of chlorpyrifos and control samples.

\begin{tabular}{|c|c|c|c|c|c|c|}
\hline \multirow{2}{*}{ Doses } & \multicolumn{5}{|c|}{ Number of Weeks } & \multirow[b]{2}{*}{6} \\
\hline & 1 & 2 & 3 & 4 & 5 & \\
\hline D1 & 0 & $0.67 \pm 0^{*}$ & $1.34 \pm 0.04 *$ & $1.36 \pm 0.10^{*}$ & $1.12 \pm 0.03 *$ & $0.6 \pm 0^{*}$ \\
\hline D2 & 0 & 0 & $1.5 \pm 0.08 *$ & $1.37 \pm 0.05^{*}$ & $0.60 \pm 0.03 *$ & 0 \\
\hline D3 & 0 & 0 & $1.36 \pm 0.06^{*}$ & $1.25 \pm 0.11 *$ & $0.62 \pm 0.08 *$ & 0 \\
\hline D4 & 0 & 0 & $1.3 \pm 0 *$ & $1.20 \pm 0 *$ & $1 \pm 0 *$ & 0 \\
\hline Control & $1.7 \pm 0.06$ & $1.9 \pm 0.07$ & $2.5 \pm 0.13$ & $3.4 \pm 0.07$ & $1.6 \pm 0.17$ & $1.0 \pm 0$ \\
\hline
\end{tabular}

D1, D2, D3 and D4 are the chlorpyrifos dose samples i.e. $2.5,5,7.5,10 \mathrm{ml} / 1000 \mathrm{ml}$; Values are Mean \pm S.E of four replicates;

*Values are significant at $5 \%$ level of significance 
Table 3. Juvenile production rate (juveniles/ cocoon/ week) for E. eugeniae in different doses of chlorpyrifos.

\begin{tabular}{cccccccc}
\hline \multirow{2}{*}{ Doses } & \multicolumn{7}{c}{ Number of Weeks } \\
\cline { 2 - 8 } & $\mathbf{1}$ & $\mathbf{2}$ & $\mathbf{3}$ & $\mathbf{4}$ & $\mathbf{5}$ & $\mathbf{6}$ & $\mathbf{7}$ \\
\hline D1 & - & - & - & - & $0.85 \pm 0.13^{*}$ & $0.87 \pm 0.09^{*}$ & $0.5^{*}$ \\
D2 & - & - & - & - & $0.72 \pm 0.18^{*}$ & $0.64 \pm 0.09^{*}$ & - \\
D3 & - & - & - & - & $0.73 \pm 0.07^{*}$ & $0.58 \pm 0.06^{*}$ & - \\
D4 & - & - & - & - & $0.60 \pm 0^{*}$ & $0.5 \pm 0^{*}$ & - \\
Control & - & - & - & $1.35 \pm 0.024$ & $1.29 \pm 0.28$ & $1.39 \pm 0.05$ & $1.8 \pm 0.10$ \\
\hline
\end{tabular}

D1, D2, D3 and D4 are the chlorpyrifos dose samples i.e. $2.5,5,7.5,10 \mathrm{ml} / 1000 \mathrm{ml}$; Values are Mean \pm S.E of four replicates; $*$ Values are significant at $5 \%$ level of significance

Table 4. Effect of chlorpyrifos on survival and growth E. eugeniae hatchlings.

\begin{tabular}{|c|c|c|c|c|c|c|c|c|}
\hline \multirow{2}{*}{ Doses } & \multicolumn{8}{|c|}{ Number of Weeks } \\
\hline & 1 & 2 & 3 & 4 & 5 & 6 & 7 & 8 \\
\hline D1 & 100 & 100 & 100 & 100 & 100 & 100 & 100 & 75 \\
\hline D2 & 100 & 100 & 100 & 100 & 75 & 75 & 50 & 50 \\
\hline D3 & 100 & 100 & 75 & 75 & 50 & 50 & 50 & 50 \\
\hline D4 & 100 & - & - & - & - & - & - & - \\
\hline Control & 100 & 100 & 100 & 100 & 100 & 100 & 100 & 100 \\
\hline
\end{tabular}

D1, D2, D3 and D4 are the chlorpyrifos dose samples i.e. $2.5,5,7.5,10 \mathrm{ml} / 1000 \mathrm{ml}$

Table 5. Weekly changes in body weight ( $\mathrm{g}$ ) of hatchlings of E. eugeniae in chlorpyrifos.

\begin{tabular}{|c|c|c|c|c|c|c|c|c|}
\hline \multirow[t]{2}{*}{ Dose Samples } & \multicolumn{8}{|c|}{ Number of Weeks } \\
\hline & 1 & 2 & 3 & 4 & 5 & 6 & 7 & 8 \\
\hline D1 & $0.047 \pm 0.01$ & $0.050 \pm 0.01$ & $0.070 \pm 0.02$ & $0.085 \pm 0.02$ & $0.090 \pm 0.03$ & $0.14 \pm 0.04 *$ & $0.14 \pm 0.04 *$ & $0.16 \pm 0.04 *$ \\
\hline $\mathrm{D} 2$ & $0.035 \pm 0.01$ & $0.050 \pm 0.01$ & $0.045 \pm 0.014$ & $0.060 \pm 0.02$ & $0.065 \pm 0.025$ & $50.22 \pm 0.03 *$ & $0.13 \pm 0.02 *$ & $0.13 \pm 0.03^{*}$ \\
\hline D3 & $0.035 \pm 0.00$ & $0.053 \pm 0.01$ & $0.060 \pm 0.02$ & $0.20 \pm 0.05$ & $0.18 \pm 0.05$ & $0.22 \pm 0.04 *$ & $0.22 \pm 0.04 *$ & $0.30 \pm 0.04 *$ \\
\hline D4 & $0.033 \pm 0.00$ & - & - & - & - & - & - & - \\
\hline Control & $0.050 \pm 0.013$ & $0.05 \pm 20.01$ & $0.060 \pm 0.01$ & $0.070 \pm 0.02$ & $0.149 \pm 0.02$ & $0.19 \pm 0.02 *$ & $0.35 \pm 0.03 *$ & $0.40 \pm 0.007 *$ \\
\hline
\end{tabular}

D1, D2, D3 and D4 are the chlorpyrifos dose samples i.e. $2.5,5,7.5,10 \mathrm{ml} / 1000 \mathrm{ml}$; Values are Mean \pm S.E of four replicates; $*$ Values are significant at $5 \%$ level of significance; All the hatchlings died in the 4 th dose samples after one week of rearing

Table 6. Duration of life span of juveniles of E. eugeniae in chlorpyrifos and control sample.

\begin{tabular}{cc}
\hline Dose Sample & Number of days \\
\hline D1 & $43.25 \pm 0.82$ \\
D2 & $45.75 \pm 0.82$ \\
D3 & $54.25 \pm 0.82$ \\
D4 & All died after $1^{\text {st }}$ week \\
Control & $28.75 \pm 0.82$ \\
\hline
\end{tabular}

ing the present investigations. Similar reduction in body weight by increased concentration of malathion on E. fetida has been reported (Espinoza-Navarro and Bustos-Obregon, 2005). The loss of weight along with signs and symptoms of toxicity such as coiling, swollen body, sluggish movements and discharge of coelomic fluid was observed in Lumbricus terrestris when exposed to pesticides (Cyren, Ridomil, Triplen and Mamba) for 4 weeks (Ahmed, 2013). Fecundity in earthworms is sensitive to insecticides even though population densities of earthworms may not be immediately affected, there can be reproductive changes which may reduce populations in the longer term. Reduction in fecundity was observed in E. fetida on exposure to neonicotinoids (Wang et al., 2015). Low reproduction of earthworm was seen in finely sieved soil as compared to sandy soil indicating that porosity of soil may influence earthworm mobility and gaseous exchange, thus affecting its life cycle.

In the present study, as minimum numbers of cocoons were collected from D3 and D4 dose relating the reduction to the high concentration of insecticide. It is further inferred that exposure of earthworm Eudrilus to insecticide chlorpyrifos severely impairs the cocoon production and is dose-independent. Contaminated dose samples have delayed cocoon production and it has been suggested that cocoon production rates were particularly sensitive during early period of reproduction (Sprugeon and Hopkin, 1999). Similarly, exposure of worms to higher sub lethal dose of malathion produced lesser number of cocoons and hatchling than the worms exposed to lower sub lethal concentration of malathion (Rai and Bansiwal, 2009). Reproduction toxicity was also observed in case of E. fetida following exposure to deltamethrin and fenvalerantein soil (Song et al., 2015).

The lesser number of hatchlings produced in each chlorpyrifos treated sample as compared to control in the present study, is due to the elevated levels of insec- 
ticide. Percentage of high insecticide influences the reproduction parameters i.e. coccon production, mean and maximum number of hatchlings per cocoon, and a longer incubation period of worms in a dose dependent manner as observed by earlier workers (Booth and O'Halloran, 2000; Gupta and Saxena, 2003; Yasmin and D' Souza, 2007). The results of the present study correlate strongly and suggest that there being a direct relationship between dose treated and emergence of hatchlings from each cocoon.

High mortality percentage of juveniles shows the sensitivity of juveniles to elevated levels of insecticide. The estimation of various biochemical parameters was not in the preview of the present experimental design, but it is hypothesized that since newborn and younger animals are more sensitive to toxicants than older or mature animals (Rozman et al., 2001; Singh and Rishi 2005) they are affected more acutely and within a shorter exposure period. The detoxification mechanisms of juvenile animals in general may also not be as well developed as those of adult animal. It is assumed for earthworms, there may be a biochemical basis for increased sensitivity of juveniles (Matsumura, 1975).

Decrease in biomass seems to be a sensitive endpoint because it was possible to detect decreases in biomass even at low concentrations of insecticides. Our study suggests that weight loss in earthworms occurred due to some exclusive factors like inactivity, as direct response to the insecticide or as a mechanism of avoidance. The observation (Capoweiz et al., 2005) was similar to our results and this leads to prospective conclusion that weight loss in earthworms was a sensitive biomarker for exposure to insecticides even at low concentrations. It has been observed that earthworms gain more weight when exposed to sub lethal dose of malathion in comparison when exposed to higher sub lethal dose of malathion(Rai and Bansiwal, 2009). Thus the exposure to different insecticides leads to similar weight gain options.

High concentration of chlorpyrifos strongly accounts for the longer duration of days to reach maturity this is due to the physiological stress on the animal leading to a decreased energy level for maintenance, growth and the two reproductive processes i.e.differentiation to reach maturity and cocoon (egg) production (Kooijman, 1986). Our study revealed that high dose of insecticide caused the increase in duration of life span of juveniles in all the chlorpyrifos treated samples as compared to control prolonging the life cycle of the earthworm. Selection of life history parameters can be of relevance when populations are exposed to factors (such as pollutants) that reduce survival and lower reproductive effort (Charlesworth 1980). Slow maturation in earthworms exposed to contaminated soil samples has also been observed earlier (Sprugeon and Hopkins, 1999; Spurgeon et al., 2004).

\section{Conclusion}

The earthworm is the major soil mega fauna to be exposed to soil contaminants and their presence is an indicator of soil health.The present study investigated the effect of chlorpyrifos on survival, growth and reproductive potential in earthworms. The higher dose $(7.5 \mathrm{ml} / 1000 \mathrm{ml}$ and $10.0 \mathrm{ml} / 1000 \mathrm{ml})$ of chlorpyrifos was detrimental to the growth and reproductive performance in the earthworms while low and recommended doses could be used for soil application. However, to investigate the effects on higher trophic levels we need to acquire more knowledge on the chemical nature, mode of action, and means of degradation of pesticides in soil.

\section{ACKNOWLEDGMENTS}

The authors are thankful to the Head, Department of Zoology, PAU, Ludhiana, for providing the necessary facilities for research work.

\section{REFERENCES}

Ahmed, S. T. (2013). The impact of four pesticides on the earthworm Lumbricus terrestris (annelida; oligochaeta). IJCRR. 5(21): 1-5.

Bartllet, M. D., Briones, M. J. J., Neilson, R., Schmidt, O., Sprugeon, D. and Creamer, R. E., (2010). A critical review of current methods in earthworm ecology: from individuals to populations. Eur. J. Soil. Biol. 46:67-73.

Booth, L. H. and O'Halloran, K. (2000). A comparsion of biomarker responses in the earthworm Aporrectodea caliginosa to the organophosphorus insecticides diazinon and chlorpyrifos. Ecotoxicol. Toxicol. Chem. 20:2494-2502.

Capoweiz, Y., Bastardie, F. and Costagliola, G. (2005) Sub lethal effects of imidacloprid on the burrowing behavior of two earthworm species: modifications of the 3D burrow systems in artificial cores and consequences on gas diffusion in soil. Soil Biol. Biochem. 38:285-293.

Charlesworth, B. (1980). Evolution in age structural populations (Cambridge University Press).

Espinoza- Navarro, O. and Bustos- Obregon, E. (2005). Effect of malathion on the male reproductive organs of earthworms E. fetida. Asian J. Androl. 7:97-101.

Georgescu, B. and Werber, C. (2007). The role of earthworms as biological indicators of soil contamination, Bulletin. Environ. Contam. USAMV-CN. 63-64.

Gupta, S. K. and Saxena, P. N. (2003). Carbaryl - induced behavioral and reproductive abnormalities in the earthworm Metaphire posthuma: a sensitive model, alternatives to laboratory animals. 31: 587-593.

Haque, A. and Ebing, W. (1983). Toxicity determination of pesticides to earthworms in the soil substrate. J. Plant Dis. Protect. 90:395-408.

Jouquet, P., Plumere, T., Thu, T. D., Rumpel, C., Duc, T. T. and Orange, D. (2010) The rehabilitation of tropical soils using compost and vermicompost is affected by the presence of endogeic earthworms. Appl. Soil Ecol. 46:125-133.

Kooijman, S. A. L. M. (1986). Energy budget models can 
explain body size relations. J. Theor. Biol. 121:268-282.

Kurawar, R. (2010). Effects of few pesticides on earthworm activity and soil fertity, Ph.D. Thesis, M. L. S. University, Udaipur.

Lourenco, J. I. , Pereira, R. O., Silva, A. C., Morgado, J. M., Carvalho, F. P., Oliveira, J. M., Malta, M. P., Paiva, A. A., Mendo, S. A. and Goncalves, F. J. (2011) Genotoxic endpoints in the earthworms sub lethal assay to evaluate natural soils contaminated by metals and radionuclides. J. Hazard. Mater. 186(1):788-95.

Matsumura, F. (1975). Toxicity of insecticides. Plenum Press, New York.

Muir, D. C. G., Teixeira, C. and Wania, F. (2004). Empirical and modeling evidence of regional atmospheric transport of current-use pesticides. Environ. Toxicol. Chem. 23: $2421-2432$.

Muthuviveganandavel, V., Muthuraman, P., Muthu, S. and Srikumar, K. (2008). Toxic effects of carbendazin at low dose levels in male rats. J. Toxicol. Sci. 33:25-30.

Olvera-Velona, A., Capoweiz, Y., Mascle, O., Ortiz- Hermandaz L and Benoit, P. (2008). Assessment of the toxicity of ethyl-parathion to earthworm (Aporrectodea caliginosa) using behavioral, physiological and biochemicals markers. Appl. Soil Ecol. 40:476-483.

Ouellet, G., Lapen, D. R., Topp, E. and Sawada, M. (2008) A heuristic model to predict earthworm biomass in agroecosystems based on selected management and soil properties. Appl. Soil Ecol. 39: 35-45.

Rai, N. and Bansiwal, K. (2009). Impact of sub lethal doses of an organophosphate pesticide-malathion on growth and reproduction of earthworm Eisenia fetida (Savigny 1826). J. Environ. Sci. 3:87.

Ricketts, H. J., Morgan, A. J., Spurgeon, D. J. and Kille, P. (2004). Measurement of annetocin gene expression: a new reproductive biomarker in earthworm ecotoxicol- ogy. Ecotoxicol. Environ. Saf. 57: 4-10.

Rozman, K. K., Doull, J. and Hayes W. J. ( 2001). Dose, time and other factors influencing toxicity. In: Kriegler, R., Doull, J., Ecobichon, D., Gammon, D., Hodgson, E., Reiter, L., Ross, J. (ed), Handbook of pesticide toxicology, vol. 1: Principles (2nd ed). San Diego: Academic Press. pp 1-95.

Sahu, S. K. and Senapati, B. K. (1988). Alternative proposals for quantification of reproduction in a tropical earthworm. Trop. Ecol. 29:6-14.

Singh, M. and Rishi, S. (2005). Plasma acetyl cholinesterase as a biomarker of triazophos neurotoxicity in young and adult rats, Environ. Toxicol. Pharmacol. 19:147.

Song, Y., Kai, J., Song, X., Zhang, W. and Li, L. (2015). Long-term toxic effects of deltamethrin and fenvalerante in soil. J. Hazard. Mater. 289: 158-164.

Sprugeon, D. J. and Hopkin, S. P. (1999). Life - history patterns in reference and metal - exposed earthworm populations. Ecotoxicol. 8:133-141.

Spurgeon, D. J., Sturzenbaum, S. R., Svendsen, C., Hankard, P. K., Morgan, A. J., Weeks, J. M. and Kille, P. (2004). Toxicological, cellular and gene expression responses in earthworms exposed to copper and cadmium. Comp. Biochem. Phys. 138:11-21.

Suthar, S., Singh, S. and Dhawan, S. (2008). Earthworms as bioindicator of metals $(\mathrm{Zn}, \mathrm{Fe}, \mathrm{Mn}, \mathrm{Cu}, \mathrm{Pb}$ and $\mathrm{Cd})$ in soils: is metal bioaccumulation affected by their ecological category. Ecol. Engine. 32:99-107.

Wang, K., Pang, S., Mu, X., Qi, S., Li, D., Cui, F. and Wang, C. (2015). Biological response of earthworm, Eisenia fetida, to five neonicotinoid insecticides. Chemosphere. 132: $120-126$.

Yasmin, S. and D' Souza, (2007). Effect of pesticides on the reproductive output of Eisenia fetida. Bull. Environ. Contam. Toxicol. 79: 529-532. 